\title{
Effect of Thermospermine on the Growth and Expression of Polyamine-Related Genes in Rice Seedlings
}

\author{
Minaho Miyamoto, Satoshi Shimao, Wurina Tong, Hiroyasu Motose and Taku Takahashi * \\ Graduate School of Natural Science and Technology, Okayama University, Okayama 700-8530, Japan \\ * Correspondence: perfect@cc.okayama-u.ac.jp; Tel.: +81-86-251-7858
}

Received: 31 May 2019; Accepted: 5 August 2019; Published: 6 August 2019

check for updates

\begin{abstract}
A mutant defective in the biosynthesis of thermospermine, acaulis5 (acl5), shows a dwarf phenotype with excess xylem vessels in Arabidopsis thaliana. Exogenous supply of thermospermine remarkably represses xylem differentiation in the root of seedlings, indicating the role of thermospermine in proper repression of xylem differentiation. However, the effect of thermospermine has rarely been investigated in other plant species. In this paper, we examined its effect on the growth and gene expression in rice seedlings. When grown with thermospermine, rice seedlings had no clearly enlarged metaxylem vessels in the root. Expression of OsACL5 was reduced in response to thermospermine, suggesting a negative feedback control of thermospermine biosynthesis like in Arabidopsis. Unlike Arabidopsis, however, rice showed up-regulation of phloem-expressed genes, OsHB5 and OsYSL16, by one-day treatment with thermospermine. Furthermore, expression of OsPAO2 and OsPAO6, encoding extracellular polyamine oxidase whose orthologs are not present in Arabidopsis, was induced by both thermospermine and spermine. These results suggest that thermospermine affects the expression of a subset of genes in rice different from those affected in Arabidopsis.
\end{abstract}

Keywords: Arabidopsis; phloem; rice; spermine; thermospermine; xylem

\section{Introduction}

Thermospermine synthase is encoded by the ACAULIS5 (ACL5) gene in Arabidopsis thaliana [1] and its loss-of-function mutant $a c l 5$ shows a stunted growth along with excess xylem vessels [2-5]. The point-mutated acl5 mRNA level is increased in acl5 but is reduced by exogenous thermospermine [6], suggesting a negative feedback control of thermospermine biosynthesis. Previous studies have revealed that thermospermine plays a role in the repression of xylem differentiation through enhancing mRNA translation of SAC51, which encodes a basic helix-loop-helix (bHLH) protein [6,7]. The SAC51 mRNA contains conserved upstream open-reading-frames (uORFs) in the $5^{\prime}$ leader region [8] and thermospermine functions in alleviating the inhibitory effect of the uORFs on the main ORF translation, although its precise mode of action remains unclear $[9,10]$. Expressions of ACL5 and a member of the $S A C 51$ family, SACL3, are directly activated by bHLH heterodimers LHW-TMO5 and LHW-T5L1 in xylem precursor cells in the root [11] and these heterodimers play a key role in auxin-induced xylem formation [12]. Because SAC51 and SACL3 in turn compete with TMO5 or T5L1 to heterodimerize with LHW [11,13], thermospermine appears to be a part of the negative feedback regulation of auxin-induced xylem formation and thermospermine biosynthesis [14-16]. These results have been obtained solely from studies in Arabidopsis and, except for a study that reported on the negative feedback regulation of thermospermine homeostasis in poplar xylem tissues [17] and that showed the dwarf phenotype of cotton plants by silencing of GhACL5 [18], the role of thermospermine in plant development has rarely been investigated in other plant species so far. 
On the other hand, genes involved in polyamine biosynthesis and catabolism have been increasingly characterized in rice. Phylogenetic relationships based on recent studies together with the information of rice and Arabidopsis genome databases reveal that the rice genome has one gene for spermidine synthase, OSSPDS, one gene for thermospermine synthase, OsACL5, and two genes for spermine synthase, OsSPMS1 and OsSPMS2 (Figure 1A). Six putative genes for S-adenosylmethinine decarboxylase (SAMDC/AdoMetDC) are present in rice [19-21], among which two encode very short deduced polypeptides and may represent pseudo-genes. In Arabidopsis, SAMDC4 has been suggested to be tightly involved in the biosynthesis of thermospermine because its expression is limited to vasculature and decreased by thermospermine and its loss-of-function mutant, bud2, shows a dwarf phenotype similar to that of acl5 [22,23]. The orthologous gene in rice may be OsSAMDC3 (Figure 1B). There are seven genes for polyamine oxidase (PAO) in rice [24-26]. OsPAO2, OsPAO6, and OsPAO7, may encode apoplastic enzymes catalyzing the terminal catabolism reaction [27] while their closest homolog in Arabidopsis, AtPAO1, encodes a cytoplasmic enzyme catalyzing the back-conversion of thermospermine or spermine to spermidine [28]. In Arabidopsis, PAO5 is specifically expressed in vasculature and may be preferentially involved in the degradation of thermospermine [29-32]. The orthologous gene in rice appears to be OsPAO1 (Figure 1C) [25,33]. According to the above-mentioned references and molecular phylogenetic trees, the pathways that are or may be catalyzed by these gene products in rice and Arabidopsis are summarized in Figure 1D. Expression of these rice genes, however, remains to be investigated in terms of the response to thermospermine.

A

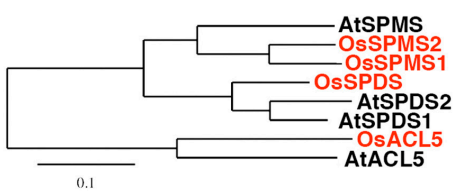

0.
B

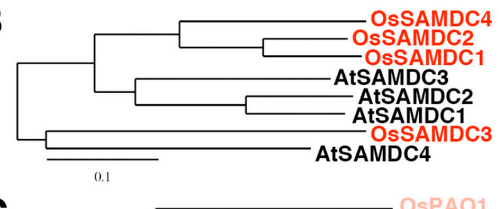

C

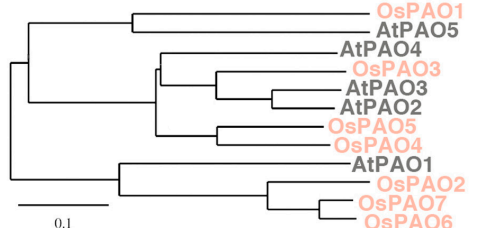

D

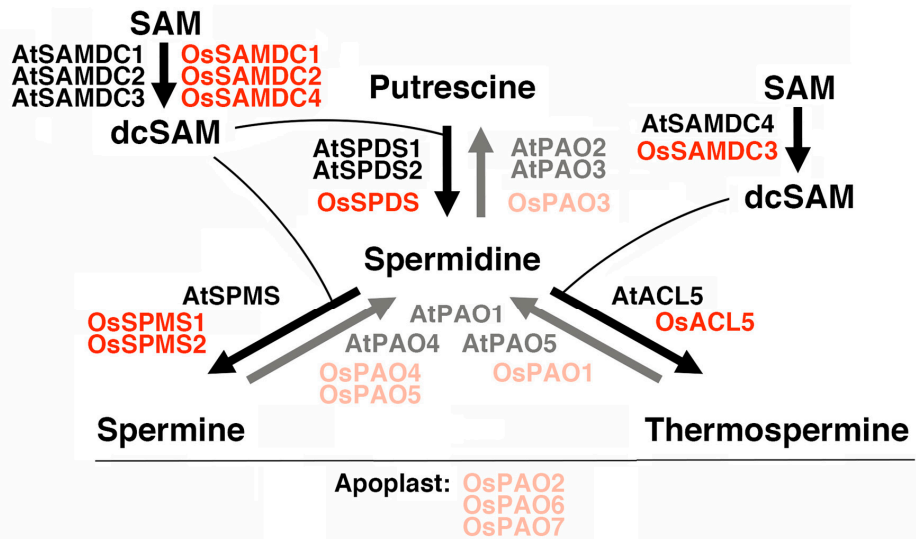

Figure 1. Polyamine biosynthetic and catabolic genes in Arabidopsis and rice. (A) Phylogenetic tree of spermidine synthase (SPDS), spermine synthase (SPMS), and thermospermine synthase (ACL5) isoforms. (B) Phylogenetic tree of $S$-adenosylmethionine decarboxylase (SAMDC) isoforms. (C) Phylogenetic tree of polyamine oxidase (PAO) isoforms. All trees based on the deduced amino acid sequences were constructed using ClustalW with the neighbor-joining method in the DNA Data Bank of Japan (DDBJ) website. The scale bar indicates the number of amino acid substitutions per site. (D) Pathways of polyamine biosynthesis and catabolism and the name of gene products mediating each reaction. Arabidopsis proteins are shown in black and light gray and rice proteins are in red and light red. 
Within this context, we here focus on the effect of thermospermine on the growth and expression of the genes related to polyamine biosynthesis, catabolism, and vascular development in rice as a model monocotyledonous species.

\section{Results}

\subsection{Thermospermine Suppresses Xylem Vessel Expansion in the Root}

When grown for four days after germination with $50 \mu \mathrm{M}$ thermospermine, rice seedlings displayed no obvious alteration in the shoot grow th compared with those with mock or $50 \mu \mathrm{M}$ spermine (Figure $2 \mathrm{~A}$ ). However, the length of the primary root was reduced by thermospermine and also by spermine (Figure 2B), indicating that these tetraamines have an inhibitory effect on root elongation in rice. The number of crown roots was not altered by these tetraamines (Figure 2C). In Arabidopsis, exogenous supply of thermospermine severely suppresses differentiation of xylem vessels and also formation of lateral roots $[16,34]$. In rice, formation of lateral roots was not suppressed by thermospermine (Figure 2D). Microscopic observations of the cross section revealed that rice seedlings grown with thermospermine had no clearly enlarged metaxylem vessels in the root in contrast to those grown with spermine or with no polyamines (Figure 2E) while they showed normal vascular development in leaves (Figure S1).
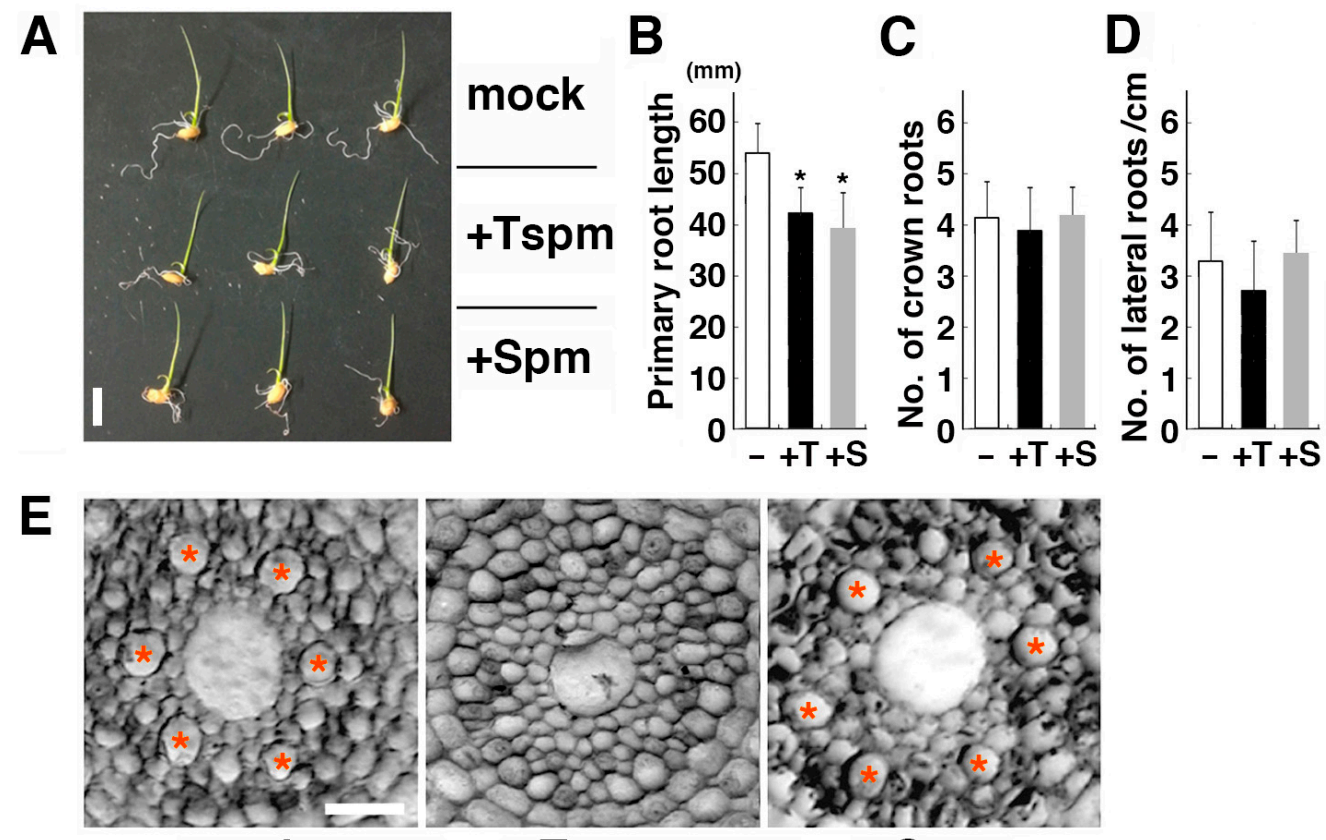

mock

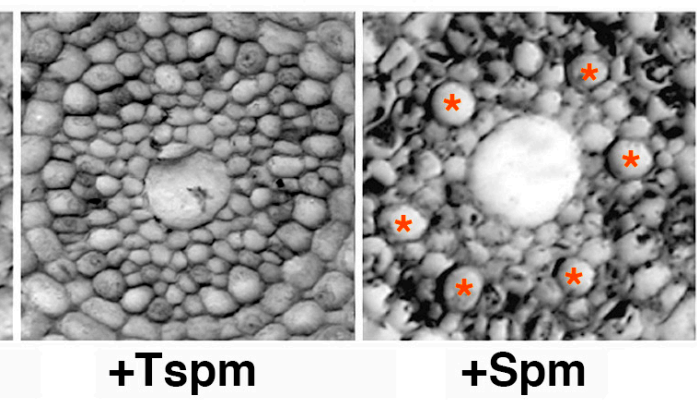

Figure 2. Effect of thermospermine and spermine on the growth of rice seedlings. (A) Four-day-old seedlings of rice grown in distilled water with no polyamines (mock), with $50 \mu \mathrm{M}$ thermospermine (+Tspm), or with $50 \mu \mathrm{M}$ spermine (+Spm). Scale bar is equivalent to $1 \mathrm{~cm}$. (B) Length of the primary root in 4-day-old rice seedlings. (C) Number of crown roots in 4-day-old rice seedlings. (D) Density of lateral roots per length of axial root in 4-day-old rice seedlings. In (B-D), seedlings were grown without polyamines (-), $50 \mu \mathrm{M}$ thermospermine (+T), or $50 \mu \mathrm{M}$ spermine (+S). Error bars represent $\mathrm{SE}$ of five independent experiments with each four seedlings per treatment. Asterisks indicate significantly different values from the control $\left({ }^{*} P<0.05\right.$, Student's $t$-test). (E) Root cross sections prepared from at a $1 \mathrm{~cm}$ distance from the root tip of 4-day-old rice seedling. Asterisks indicate xylem vessels with apparent diameter of more than $10 \mu \mathrm{m}$. Scale bar is equivalent to $20 \mu \mathrm{m}$. 


\subsection{Thermospermine Reduces OsACL5 Expression but Induces Apoplastic PAO Genes}

We examined whether expression of rice genes involved in polyamine biosynthesis and catabolism are affected by exogenous thermospermine or not. We first examined the time course of the response of OsACL5 to thermospermine in shoot and root tissues of the seedling and found that OsACL5 expression was gradually reduced in the root during treatment with $50 \mu \mathrm{M}$ thermospermine but not altered in the shoot (Figure 3A), suggesting that thermospermine biosynthesis in rice is also under negative feedback control at least in the root. We then focused on the effect of 24 -h treatment of the seedlings with thermospermine and spermine on the expression of polyamine-related genes in the root. OsACL5 was not responsive to spermine and OsSPDS, OsSPMS1, and OsSPMS2 also showed no response to thermospermine and spermine (Figure 3B). Expression of OsSAMDC2 was increased by both thermospermine and spermine, but OSSAMDC1 and OsSAMDC4 were not responsive to these polyamines (Figure 3C). Expression of OsSAMDC3, a putative ortholog of AtSAMDC4 involved in thermospermine biosynthesis (Figure 1D), was not detected in the root. On the other hand, expressions of OsPAO2 and, in particular, OsPAO6, both encoding extracellular polyamine oxidases, were drastically increased by both thermospermine and spermine while those of OsPAO3 and OsPAO4 were moderately increased by these tetraamines but OsPAO5 expression was not (Figure 3D). We detected no increase in the expression of OsPAO1, a putative ortholog of thermospermine-catabolizing AtPAO5, although a previous study has reported on its induction by thermospermine [25]. Expression of OsPAO7, which has been shown to be an anther-specific gene [27], was not detected in the root. We confirmed that expression levels of these genes were not altered by thermospermine in the above-ground part of seedlings except for those of $P A O 2$ and $P A O 6$, which were also increased by thermospermine (Figure S2).
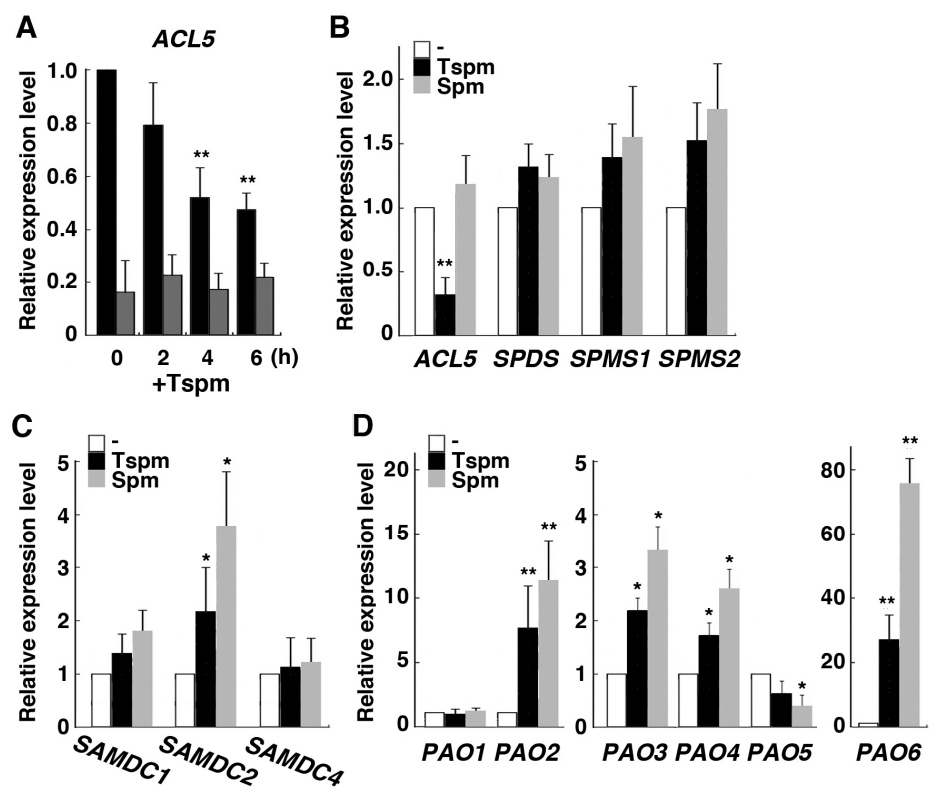

Figure 3. Effect of thermospermine and spermine on polyamine biosynthetic and catabolic genes in rice. (A) Time course changes in OsACL5 expression after treatment of 4-day-old seedlings with $50 \mu \mathrm{M}$ thermospermine (+Tspm). Black and dark gray bars represent relative expression levels in the root and those in the shoot, respectively. The level in the root before treatment is set as 1. (B) Expression levels of OsACL5, OsSPDS, OsSPMS1, and OsSPMS2. (C) Expression levels of OsSAMDC genes. (D) Expression levels of OsPAO genes. In (B-D), RNA was extracted from roots after 24-h treatment of 4-day-old seedlings with mock (white bars), $50 \mu \mathrm{M}$ thermospermine (black bars), and $50 \mu \mathrm{M}$ spermine (gray bars). The transcript levels in mock treated roots as represented by white bars are set as 1 . Error bars represent SE of three independent experiments with each performed in duplicate. Asterisks indicate significantly different values from the control level $\left({ }^{*} P<0.05,{ }^{* *} P<0.01\right.$, Student's $t$-test). 


\subsection{Expression of Phloem-Specific Genes are Increased by Thermospermine}

In Arabidopsis, thermospermine reduces expression of a number of genes involved in xylem differentiation [34], including all members of the Class III homeodomain leucine zipper (HD-Zip III) gene family, which is known to play a regulatory role in vascular development in Arabidopsis [35]. Then we examined the effect of thermospermine on the expression of vascular-related genes in rice roots. OsHB3 expression was not altered by 24-h treatment with thermospermine, while OsHB4 expression was reduced and OsHB5 expression was increased by the same treatment (Figure 4). OsHB3 and OsHB4 are the closest homologs of $P H B$ and PHV of the Arabidopsis HD-Zip III gene family and phloem-specific OsHB5 shows the highest similarity to other HD-Zip III members, ATHB8 and CNA, although expression patterns in rice are different from those in Arabidopsis [36]. We also examined expression of OsYSL16, which encodes a copper-nicotianamine transporter localized in phloem [37], and that of OsHKT1;5 encoding a sodium transporter in root xylem parenchymal cells [38]. OsYSL16 expression was increased in response to thermospermine while OsHKT1;5 showed no response (Figure 4). Furthermore, four genes belonging to the SAC51 family [39] were examined. Expression of OsSACL2 and OsSACL3C was markedly increased by 24-h treatment with thermospermine but OsSACL3B expression was reduced by thermospermine and spermine (Figure 4). In the shoot part, however, expression levels of these genes were not altered by 24-h treatment with thermospermine (Figure S2).

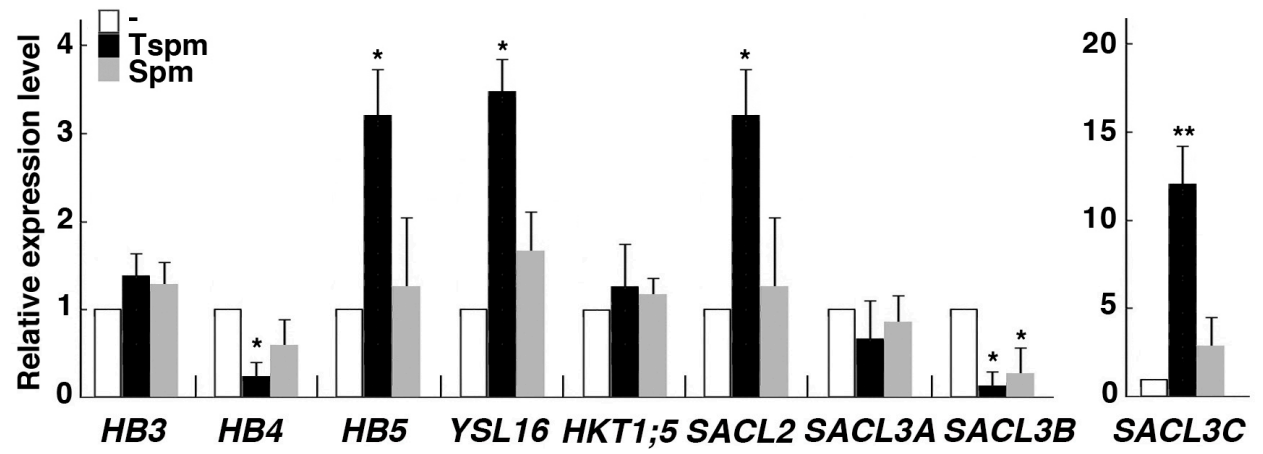

Figure 4. Effect of thermospermine and spermine on the expression of vascular-related genes in rice roots. RNA was extracted from roots sampled 24-h after treatment of 4-day-old seedlings with mock (white bars), $50 \mu \mathrm{M}$ thermospermine (black bars), and $50 \mu \mathrm{M}$ spermine (gray bars). The transcript levels in mock treated roots as represented by white bars are set as 1 . Error bars represent SE of three independent experiments with each performed in duplicate. Asterisks indicate significantly different values from the level before treatment $\left({ }^{*} P<0.05,{ }^{* *} P<0.01\right.$, Student's $t$-test $)$.

\section{Discussion}

This study provides an initial investigation of physiological and molecular effects of exogenous thermospermine in rice seedlings. We confirmed that thermospermine represses both development of metaxylem vessels and expression of OsACL5 in the root, suggesting its functional conservation between eudicots and monocots. It may be concluded that thermospermine, whose biosynthesis is under negative feedback control of the expression of a gene for thermospermine synthase, is involved in the repression of xylem development at least in the root of angiosperms. We observed no apparent effect of thermospermine on leaf vasculature and OsACL5 expression in the shoot. Optimal concentrations of thermospermine might not be reached at the site of action in the shoot probably because of the presence of apoplastic PAOs. Alternatively, it is also conceivable that in the rice shoot, vascular development is uncoupled from the function of thermospermine. In addition, lateral root formation, which is severely repressed by exogenous thermospermine in Arabidopsis, was not affected in rice. Development of the protoxylem, which plays a role in triggering lateral root initiation, might be less affected in rice than in Arabidopsis under our experimental condition of thermospermine treatment. 
In terms of root elongation, both thermospermine and spermine were shown to be inhibitory to the growth. For rice seedlings that are normally grown in water, high concentrations of these polyamines may be generally toxic to the growth. The inhibitory effect of spermine on the growth of rice seedlings has been reported previously [40]. We found that except OsACL5, expressions of many polyamine-related genes were more or less increased by both thermospermine and spermine. These include OsSAMDC2, OsPAO2, OsPAO3, OsPAO4, and OsPAO6. There is accumulating evidence suggesting the importance of PAOs, in particular, apoplastic PAOs in stress responses [41-43]. A previous study has shown that expressions of some of rice $P A O$ genes are responsive to salt stress [44]. We suggest that exogenous thermospermine and spermine may mimic the stress signal to trigger OsPAO gene activation. However, such a drastic increase in the expression of $P A O$ genes by spermine or thermospermine has not been reported for PAOs in Arabidopsis and only the AtPAO5 expression has been shown to be increased by high salt [45]. The high toxicity of exogenous polyamines in rice seedlings might be attributed to hydrogen peroxide or other products of apoplastic polyamine degradation. On the other hand, considering the function of SAMDC in providing a substrate for polyamine biosynthesis, induction of OsSAMDC2 by polyamines seems contradictory. OsSAMDC2 expression has also been shown to be increased by high salinity [21]. It is thus possible that, in water-grown rice seedlings, exogenous polycationic thermospermine and spermine are sensed as stress to induce stress-responsive genes including OsSAMDC2. How expressions of OsPAOs and OsSAMDC2 are induced by polyamines or high salt remains an open question.

Expression of OsHB5, which was increased in response to thermospermine, is in contrast to that of ATHB8 and CNA in Arabidopsis, which are reduced by thermospermine [34]. This might be related to different tissue expression patterns of HD-Zip III genes between rice and Arabidopsis. Importantly, expression of phloem-specific OsYSL16 was also increased by thermospermine. This suggests a possibility that thermospermine is involved not only in repressing xylem development but also in promoting phloem development in rice. So far we have obtained no cytological evidence of the role of thermospermine in phloem development and it should be pursued in future work. Furthermore, among the members of the SAC51 family, OSSACL2 and OSSACL3C were up-regulated by thermospermine while $S A C L 3 B$ was down-regulated. Our recent study has shown that $5^{\prime}$ leader regions of OsSACL3A and OsSACL3C mRNAs can be responsive to thermospermine in terms of enhancing translation of the downstream reporter in transgenic Arabidopsis [39] while no genes that are transcriptionally and specifically up-regulated by thermospermine have been identified in Arabidopsis. Tissue-specific expression patterns of the rice $S A C 51$ family genes remain to be investigated.

In conclusion, our results revealed that thermospermine plays a repressive role in xylem vessel development in the root of rice seedlings and it also affects expression of a subset of genes that are different from those reduced in Arabidopsis. This difference might be largely due to the presence of apoplastic PAOs in rice, whose gene expression was found to be strongly induced by both thermospermine and spermine.

\section{Materials and Methods}

\subsection{Chemicals}

Spermine- $4 \mathrm{HCl}$ and thermospermine- $4 \mathrm{HCl}$ were obtained from Nakarai Chemicals (Kyoto, Japan) and Santa Cruz Biotechnology (Santa Cruz, CA, USA), respectively.

\subsection{Plant Material and Growth Conditions}

The rice Oryza sativa L. cv. Nipponbare was used throughout this work. Seeds were sown in Petri dishes containing distilled water and incubated at $22{ }^{\circ} \mathrm{C}$ on an orbital shaker at $60 \mathrm{rpm}$ under $16 \mathrm{~h}$ light $/ 8 \mathrm{~h}$ dark condition. The dishes were arranged as a single layer in a randomized complete block design. The growth experiments were repeated five times with each four seedlings per treatment. 


\subsection{Preparation of Sections and Microscopy}

Root tissues were fixed in FAA ( $45 \%$ ethanol, $4 \%$ formaldehyde, $5 \%$ acetic acid), dehydrated through an ethanol series, and embedded in Technovit 7100 resin (Heraeus Kulzer, Wehrheim, Germany). Samples were sectioned into $10 \mu \mathrm{m}$-thick slices by a rotary microtome (RM2245, Leica Microsystems, Wetzlar, Germany) equipped with a tungsten carbide disposable blade (TC65, Leica). Sections were stained with $0.5 \%$ Toluidine blue and observed under a differential interference contrast microscope (SMZ-ZT-1, Nikon, Tokyo, Japan).

\subsection{RNA Preparation and RT-PCR}

Total RNA was extracted from tissues with mortar and pestle in the presence of liquid nitrogen and isolated by using NucleoSpin RNA Plant kit (Macherey-Nagel, Düren, Germany) according to the manufacture's instruction. Each RNA sample was prepared three times independently. The resulting RNA solution was treated with RNase-free DNase I (Takara, Kyoto, Japan). First-strand cDNA was synthesized using PrimeScript II 1st strand cDNA synthesis kit (Takara) with an oligo (dT) primer. Quantitative real-time PCR was performed using KAPA SYBR Fast qPCR kit (Kapa Biosystems, Woburn, MA, USA) with gene-specific primers (Tables 1 and 2) in a Thermal Cycler Dice TP760 System (Takara). OsACT1 [46] was used as an internal control. All RT-PCR experiments were done in duplicate using three distinct cDNA preparations per sample.

\subsection{Phylogenetic Analysis}

Deduced protein sequences were aligned by ClustalW and phylogenetic trees were constructed using the neighbor-joining method in the DDBJ website (http://clustalw.ddbj.nig.ac.jp/index.php?lang=ja). The trees were visualized by TreeDyn (http://www.phylogeny.fr/one_task.cgi?task_type=treedyn). Accession numbers of rice genes are listed in Table 1 and those of Arabidopsis genes are AtACL5, At5g19530; AtSPDS1, At1g23820; AtSPDS2, At1g70310; AtSPMS, At5g53120; AtSAMDC1, At3g02470; AtSAMDC2, At5g15950; AtSAMDC3, At3g25570; AtSAMDC4, At5g18930; AtPAO1, At5g13700; AtPAO2, At2g43020; AtPAO3, AT3G59050; AtPAO4, AT1G65840; and AtPAO5, AT4G29720.

Table 1. List of polyamine biosynthetic and catabolic genes examined in this study and primer sequences used for RT-PCR.

\begin{tabular}{|c|c|c|c|}
\hline Gene Name & Locus ID & MSU ID & Primer Sequence \\
\hline \multirow{2}{*}{ OsSPDS } & \multirow{2}{*}{ Os07g0408700 } & \multirow{2}{*}{ LOC_Os07g22600 } & F: CAACATACCCTAGTGGTGTT \\
\hline & & & R: CTAGTTGGCCTTGGATCCAA \\
\hline \multirow{2}{*}{ OsSPMS1 } & \multirow{2}{*}{ Os06g0528600 } & \multirow{2}{*}{ LOC_Os06g33710 } & F: CCTGAAGGGAAATATGATGC \\
\hline & & & R: AATGACACCACTAGGATAGG \\
\hline \multirow{2}{*}{ OsSPMS2 } & \multirow{2}{*}{ Os02g0254700 } & \multirow{2}{*}{ LOC_Os02g15550 } & F: CGACATATCCCAGTGGTGTG \\
\hline & & & R: CAATACGCCTCTAGCTCTCT \\
\hline \multirow{2}{*}{ OsACL5 } & \multirow{2}{*}{ Os02t0237100 } & \multirow{2}{*}{ LOC_Os02g14190 } & F: AAGAGTAGGGAGAAGTTCGA \\
\hline & & & R: GTGTATGCTTTGACATACTTGA \\
\hline \multirow{2}{*}{ OsSAMDC1 } & \multirow{2}{*}{ Os04g0498600 } & \multirow{2}{*}{ LOC_Os04g42095 } & F: ACTCCAACTGCGCGAAGAAG \\
\hline & & & R: CAGCAGCAGACAAGACACCC \\
\hline \multirow{2}{*}{ OsSAMDC2 } & \multirow{2}{*}{ Os02g0611200 } & \multirow{2}{*}{ LOC_Os02g39795 } & F: GCTTACTCCAACTGCGCGAG \\
\hline & & & R: CGCCGAGACCGGTGGAGAGT \\
\hline \multirow{2}{*}{ OsSAMDC3 } & \multirow{2}{*}{ Os05g0141800 } & \multirow{2}{*}{ LOC_Os05g04990 } & F: GTGGTGGACGAGAATGACCC \\
\hline & & & R: CTAGTTGTCATGCTCATGCT \\
\hline
\end{tabular}


Table 1. Cont.

\begin{tabular}{|c|c|c|c|}
\hline Gene Name & Locus ID & MSU ID & Primer Sequence \\
\hline \multirow{2}{*}{ OsSAMDC4 } & \multirow{2}{*}{ Os09g0424300 } & \multirow{2}{*}{ LOC_Os09g25625 } & F: TGCTTACTCCAACTGCGCTC \\
\hline & & & R: CATAGCCTTCAAACCCAATG \\
\hline \multirow{2}{*}{ OsPAO1 } & \multirow{2}{*}{ Os01g0710200 } & \multirow{2}{*}{ LOC_Os01g51320 } & F: TTCCTCGGGTCATACAGCTA \\
\hline & & & R: CTACGTGGTGTGATTCGCTC \\
\hline \multirow{2}{*}{ OsPAO2 } & \multirow{2}{*}{ Os03g0193400 } & \multirow{2}{*}{ LOC_Os03g09810 } & F: CCCAGATTCCAATGTTCTTC \\
\hline & & & R: GCAGAGTCAATACCTGCAAG \\
\hline \multirow{2}{*}{ OsPAO3 } & \multirow{2}{*}{ Os04g0623300 } & \multirow{2}{*}{ LOC_Os04g53190 } & F: CTGCCGAGCCGATACATTAC \\
\hline & & & R: CATCTCCAGCATGTCCAGCT \\
\hline \multirow{2}{*}{ OsPAO4 } & \multirow{2}{*}{ Os04g0671200 } & \multirow{2}{*}{ LOC_Os04g57550 } & F: CCACTGAACCTACGAAGTAT \\
\hline & & & R: ATCTCCTCGTAGGCCTTGAC \\
\hline \multirow{2}{*}{ OsPAO5 } & \multirow{2}{*}{ Os04g0671300 } & \multirow{2}{*}{ LOC_Os04g57560 } & F: GCTACTGAACCGGTCCAGTA \\
\hline & & & R: GGAAAAGGTCGGAGATGCCT \\
\hline \multirow{2}{*}{ OsPAO6 } & \multirow{2}{*}{ Os09g0368200 } & \multirow{2}{*}{ LOC_Os09g20260 } & F: ACGGAGTCTGGCAGGAGTTT \\
\hline & & & R: CGCCCTGAGCTGGTCATAC \\
\hline \multirow{2}{*}{ OsPAO7 } & \multirow{2}{*}{ Os09g0368500 } & \multirow{2}{*}{ LOC_Os09g20284 } & F: ACGGAGTCTGGCAGGAGTTT \\
\hline & & & R: CGCCCTGAGCTGGTCATGT \\
\hline
\end{tabular}

Table 2. List of other genes and their primer sequences used for RT-PCR.

\begin{tabular}{|c|c|c|c|}
\hline Gene Name & Locus ID & MSU ID & Primer Sequence \\
\hline \multirow{2}{*}{ OsHB3 } & \multirow{2}{*}{ Os12g0612700 } & \multirow{2}{*}{ LOC_Os12g41860 } & F: GATCATGCAGCAGGGTTTCA \\
\hline & & & R: ATACGGTGGTGGTATTCAGG \\
\hline \multirow{2}{*}{ OsHB4 } & \multirow{2}{*}{ Os03g0640800 } & \multirow{2}{*}{ LOC_Os03g43930 } & F: CTGCTCCCTGAAGGCTGCTC \\
\hline & & & R: ATGACCAGTTGACGAACATG \\
\hline \multirow{2}{*}{ OsHB5 } & \multirow{2}{*}{ Os01g0200300 } & \multirow{2}{*}{ LOC_Os01g10320 } & F: CAACATCATGGAGCAGGGGA \\
\hline & & & R: TGTACACGCTGTTTCATGAG \\
\hline \multirow{2}{*}{ OsYSL16 } & \multirow{2}{*}{ Os04g0542800 } & \multirow{2}{*}{ LOC_Os04g45900 } & F: CTTAACAACAGAGTGGCGGA \\
\hline & & & R: AGAGCGCGATCTTGCCGTAG \\
\hline \multirow{2}{*}{ OsHKT1;5 } & \multirow{2}{*}{ Os01g0307500 } & \multirow{2}{*}{ LOC_Os01g20160 } & F: CGAGGTTATCAGTGCGTATG \\
\hline & & & R: GCATGGGTGCTTGCAGTTAG \\
\hline \multirow{2}{*}{ OsSACL2 } & \multirow{2}{*}{ Os03g0391700 } & \multirow{2}{*}{ LOC_Os03g27390 } & F: CCCAAGATTGCCAGGCCGAG \\
\hline & & & R: GGATCCCATCAAGAAACAACCA \\
\hline \multirow{2}{*}{ OsSACL3A } & \multirow{2}{*}{ Os03g0591300 } & \multirow{2}{*}{ LOC_Os03g39432 } & F: GCAAGTGTGCCAGGCCGAAT \\
\hline & & & R: AGATCTGGGAAAGCAGGAAATG \\
\hline \multirow{2}{*}{ OsSACL3B } & \multirow{2}{*}{ Os02g0315600 } & \multirow{2}{*}{ LOC_Os02g21090 } & F: GTCATCGTGTGAGAGCAAG \\
\hline & & & R: ACGTCACGGGCTTGAGAAG \\
\hline \multirow{2}{*}{ OsSACL3C } & \multirow{2}{*}{ Os01g0626900 } & \multirow{2}{*}{ LOC_Os01g43680 } & F: CAAGTGTGCCAGGCTGAGTA \\
\hline & & & R: GGATCCTCTACCTGATCTGATG \\
\hline \multirow{2}{*}{ OsACT1 } & \multirow{2}{*}{ Os03g0718100 } & \multirow{2}{*}{ LOC_Os03g50885 } & F: CTCCCCCATGCTATCCTTCG \\
\hline & & & R: CCATCAGGAAGCTCGTAGCT \\
\hline
\end{tabular}


Supplementary Materials: The following are available online at http://www.mdpi.com/2223-7747/8/8/269/s1, Figure S1: Effect of thermospermine on the leaf vasculature of rice seedlings, Figure S2: Effect of thermospermine on the expression of polyamine- and vascular-related genes in the shoot of 5-day-old seedlings.

Author Contributions: Conceptualization, M.M. and T.T.; Investigation, M.M. and S.S.; Validation, M.M., S.S. and W.T.; Data analysis, M.M., W.T. and T.T.; Writing—original draft preparation, M.M. and T.T.; Writing-review and editing, H.M. and T.T.; Funding acquisition, T.T.

Funding: This work was supported in part by the Japan Society for the Promotion of Science (JSPS) Grants-in-Aid for Scientific Research (Nos. 26113516 and 19K06724) to T.T.

Conflicts of Interest: The authors declare no conflict of interest.

\section{References}

1. Knott, J.M.; Römer, P.; Sumper, M. Putative spermine synthases from Thalassiosira pseudonana and Arabidopsis thaliana synthesize thermospermine rather than spermine. FEBS Lett. 2007, 581, 3081-3086. [CrossRef] [PubMed]

2. Hanzawa, Y.; Takahashi, T.; Komeda, Y. ACL5, an Arabidopsis gene required for internodal elongation after flowering. Plant J. 1997, 12, 863-874. [CrossRef] [PubMed]

3. Hanzawa, Y.; Takahashi, T.; Michael, A.J.; Burtin, D.; Long, D.; Pineiro, M.; Coupland, G.; Komeda, Y. ACAULIS5, an Arabidopsis gene required for stem elongation, encodes a spermine synthase. EMBO J. 2000, 19, 4248-4256. [CrossRef] [PubMed]

4. Clay, N.K.; Nelson, T. Arabidopsis thickvein mutation affects vein thickness and organ vascularization, and resides in a provascular cell-specific spermine synthase involved in vein definition and in polar auxin transport. Plant Physiol. 2005, 138, 767-777. [CrossRef] [PubMed]

5. Muñiz, L.; Minguet, E.G.; Singh, S.K.; Pesquet, E.; Vera-Sirera, F.; Moreau-Courtois, C.L.; Carbonell, J.; Blázquez, M.A.; Tuominen, H. ACAULIS5 controls Arabidopsis xylem specification through the prevention of premature cell death. Development 2008, 135, 2573-2582. [CrossRef] [PubMed]

6. Kakehi, J.I.; Kuwashiro, Y.; Niitsu, M.; Takahashi, T. Thermospermine is required for stem elongation in Arabidopsis thaliana. Plant Cell Physiol. 2008, 49, 1342-1349. [CrossRef] [PubMed]

7. Kakehi, J.I.; Kawano, E.; Yoshimoto, K.; Cai, Q.; Imai, A.; Takahashi, T. Mutations in ribosomal proteins, RPL4 and RACK1, suppress the phenotype of a thermospermine-deficient mutant of Arabidopsis thaliana. PLoS ONE 2015, 27, e0117309. [CrossRef]

8. Imai, A.; Hanzawa, Y.; Komura, M.; Yamamoto, K.T.; Komeda, Y.; Takahashi, T. The dwarf phenotype of the Arabidopsis ACL5-1 mutant is suppressed by a mutation in an upstream ORF of a bHLH gene. Development 2006, 133, 3575-3585. [CrossRef]

9. Vera-Sirera, F.; Minguet, E.G.; Singh, S.K.; Ljung, K.; Tuominen, H.; Blázquez, M.A.; Carbonell, J. Role of polyamines in plant vascular development. Plant Physiol. Biochem. 2010, 48, 534-539. [CrossRef]

10. Takano, A.; Kakehi, J.I.; Takahashi, T. Thermospermine is not a minor polyamine in the plant kingdom. Plant Cell Physiol. 2012, 53, 606-616. [CrossRef]

11. Katayama, H.; Iwamoto, K.; Kariya, Y.; Asakawa, T.; Kan, T.; Fukuda, H.; Ohashi-Ito, K. A negative feedback loop controlling bHLH complexes is involved in vascular cell division and differentiation in the root apical meristem. Curr. Biol. 2015, 25, 3144-3150. [CrossRef] [PubMed]

12. Ohashi-Ito, K.; Saegusa, M.; Iwamoto, K.; Oda, Y.; Katayama, H.; Kojima, M.; Sakakibara, H.; Fukuda, H. A bHLH complex activates vascular cell division via cytokinin action in root apical meristem. Curr. Biol. 2014, 24, 2053-2058. [CrossRef] [PubMed]

13. Vera-Sirera, F.; De Rybel, B.; Úrbez, C.; Kouklas, E.; Pesquera, M.; Álvarez-Mahecha, J.C.; Minguet, E.G.; Tuominen, H.; Carbonell, J.; Borst, J.W.; et al. A bHLH-based feedback loop restricts vascular cell proliferation in plants. Dev. Cell 2015, 35, 432-443. [CrossRef] [PubMed]

14. Baima, S.; Forte, V.; Possenti, M.; Peñalosa, A.; Leoni, G.; Salvi, S.; Felici, B.; Ruberti, I.; Morelli, G. Negative feedback regulation of auxin signaling by ATHB8/ACL5-BUD2 transcription module. Mol. Plant 2014, 7, 1006-1025. [CrossRef] [PubMed]

15. Yoshimoto, K.; Noutoshi, Y.; Hayashi, K.; Shirasu, K.; Takahashi, T.; Motose, H. A chemical biology approach reveals an opposite action between thermospermine and auxin in xylem development in Arabidopsis thaliana. Plant Cell Physiol. 2012, 53, 635-645. [CrossRef] [PubMed] 
16. Cai, Q.; Fukushima, H.; Yamamoto, M.; Ishii, N.; Sakamoto, T.; Kurata, T.; Motose, H.; Takahashi, T. The SAC51 family plays a central role in thermospermine responses in Arabidopsis. Plant Cell Physiol. 2016, 57, 1583-1592. [CrossRef] [PubMed]

17. Milhinhos, A.; Prestele, J.; Bollhoner, B.; Matos, A.; Vera-Sirera, F.; Rambla, J.L.; Ljung, K.; Carbonell, J.; Blázquez, M.A.; Tuominen, H.; et al. Thermospermine levels are controlled by an auxin-dependent feedback loop mechanism in Populus xylem. Plant J. 2013, 75, 685-698. [CrossRef] [PubMed]

18. Mo, H.; Wang, X.; Zhang, Y.; Yang, J.; Ma, Z. Cotton ACAULIS5 is involved in stem elongation and the plant defense response to Verticillium dahliae through thermospermine alteration. Plant Cell Rep. 2015, 34, 1975-1985. [CrossRef] [PubMed]

19. Do, P.T.; Degenkolbe, T.; Erban, A.; Heyer, A.G.; Kopka, J.; Köhl, K.I.; Hincha, D.K.; Zuther, E. Dissecting rice polyamine metabolism under controlled long-term drought stress. PLoS ONE 2013, 8, e60325. [CrossRef]

20. Chen, M.; Chen, J.J.; Fang, J.Y.; Guo, Z.F.; Lu, S.Y. Down-regulation of S-adenosylmethionine decarboxylase genes results in reduced plant length, pollen viability, and abiotic stress tolerance. Plant Cell Tissue Org. 2014, 116, 311-322. [CrossRef]

21. Saha, J.; Giri, K. Molecular phylogenomic study and the role of exogenous spermidine in the metabolic adjustment of endogenous polyamine in two rice cultivars under salt stress. Gene 2017, 609, 88-103. [CrossRef] [PubMed]

22. Ge, C.; Cui, X.; Wang, Y.; Hu, Y.; Fu, Z.; Zhang, D.; Cheng, Z.; Li, J. BUD2, encoding an S-adenosylmethionine decarboxylase, is required for Arabidopsis growth and development. Cell Res. 2006, 16, 446-456. [CrossRef] [PubMed]

23. Cui, X.; Ge, C.; Wang, R.; Wang, H.; Chen, W.; Fu, Z.; Jiang, X.; Li, J.; Wang, Y. The BUD2 mutation affects plant architecture through altering cytokinin and auxin responses in Arabidopsis. Cell Res. 2010, 20, 576-586. [CrossRef] [PubMed]

24. Ono, Y.; Kim, D.W.; Watanabe, K.; Sasaki, A.; Niitsu, M.; Berberich, T.; Kusano, T.; Takahashi, Y. Constitutively and highly expressed Oryza sativa polyamine oxidases localize in peroxisomes and catalyze polyamine back conversion. Amino Acids 2012, 42, 867-876. [CrossRef] [PubMed]

25. Liu, T.; Kim, D.W.; Niitsu, M.; Berberich, T.; Kusano, T. Oryza sativa polyamine oxidase 1 back-converts tetraamines, spermine and thermospermine, to spermidine. Plant Cell Rep. 2014, 33, 143-151. [CrossRef] [PubMed]

26. Chen, B.-X.; Li, W.-Y.; Gao, Y.-T.; Chen, Z.-J.; Zhang, W.-N.; Liu, Q.-J.; Chen, Z. Involvement of polyamine oxidase-produced hydrogen peroxide during coleorhiza-limited germination of rice seeds. Front Plant Sci. 2016, 7, 1219. [CrossRef] [PubMed]

27. Liu, T.B.; Kim, D.W.; Niitsu, M.; Maeda, S.; Watanabe, M.; Kamio, Y.; Berberich, T.; Kusano, T. Polyamine oxidase 7 is a terminal catabolism-type enzyme in Oryza sativa and is specifically expressed in anthers. Plant Cell Physiol. 2014, 55, 1110-1122. [CrossRef] [PubMed]

28. Fincato, P.; Moschou, P.N.; Spedaletti, V.; Tavazza, R.; Angelini, R.; Federico, R.; Roubelakis-Angelakis, K.A.; Tavladoraki, P. Functional diversity inside the Arabidopsis polyamine oxidase gene family. J. Exp. Bot. 2011, 62, 1155-1168. [CrossRef] [PubMed]

29. Fincato, P.; Moschou, P.N.; Ahou, A.; Angelini, R.; Roubelakis-Angelakis, K.A.; Federico, R.; Tavladoraki, P. The members of Arabidopsis thaliana PAO gene family exhibit distinct tissue and organ-specific expression pattern during seedling growth and flower development. Amino Acids 2012, 42, 831-841. [CrossRef]

30. Ahou, A.; Martignago, D.; Alabdallah, O.; Tavazza, R.; Stano, P.; Macone, A.; Rambla, J.L.; Vera-Sirera, F.; Angelini, R.; Federico, R.; et al. A plant spermine oxidase/dehydrogenase regulated by the proteasome and polyamines. J. Exp. Bot. 2014, 65, 1585-1603. [CrossRef]

31. Kim, D.W.; Watanabe, K.; Murayama, C.; Izawa, S.; Niitsu, M.; Michael, A.J.; Berberich, T.; Kusano, T. Polyamine oxidase 5 regulates Arabidopsis growth through thermospermine oxidase activity. Plant Physiol. 2014, 165, 1575-1590. [CrossRef] [PubMed]

32. Alabdallah, O.; Ahou, A.; Mancuso, N.; Pompili, V.; Macone, A.; Pashkoulov, D.; Stano, P.; Cona, A.; Angelini, R.; Tavladoraki, P. The Arabidopsis polyamine oxidase/dehydrogenase 5 interferes with cytokinin and auxin signaling pathways to control xylem differentiation. J. Exp. Bot. 2017, 68, 997-1012. [CrossRef] [PubMed] 
33. Liu, T.; Wook Kim, D.; Niitsu, M.; Berberich, T.; Kusano, T. POLYAMINE OXIDASE 1 from rice (Oryza sativa) is a functional ortholog of Arabidopsis POLYAMINE OXIDASE 5. Plant Signal Behav. 2014, 9, e29773. [CrossRef] [PubMed]

34. Tong, W.; Yoshimoto, K.; Kakehi, J.I.; Motose, H.; Niitsu, M.; Takahashi, T. Thermospermine modulates expression of auxin-related genes in Arabidopsis. Front Plant Sci. 2014, 5, 94. [CrossRef] [PubMed]

35. Prigge, M.J.; Otsuga, D.; Alonso, J.M.; Ecker, J.R.; Drews, G.N.; Clark, S.E. Class III homeodomain-leucine zipper gene family members have overlapping, antagonistic, and distinct roles in Arabidopsis development. Plant Cell 2005, 17, 61-76. [CrossRef] [PubMed]

36. Itoh, J.; Hibara, K.; Sato, Y.; Nagato, Y. Developmental role and auxin responsiveness of class III homeodomain leucine zipper gene family members in rice. Plant Physiol. 2008, 147, 1960-1975. [CrossRef] [PubMed]

37. Zheng, L.; Yamaji, N.; Yokosho, K.; Ma, J.F. YSL16 is a phloem-localized transporter of the copper-nicotianamine complex that is responsible for copper distribution in rice. Plant Cell 2012, 24, 3767-3782. [CrossRef]

38. Kobayashi, N.I.; Yamaji, N.; Yamamoto, H.; Okubo, K.; Ueno, H.; Costa, A.; Tanoi, K.; Matsumura, H.; Fujii-Kashino, M.; Horiuchi, T.; et al. OsHKT1;5 mediates $\mathrm{Na}^{+}$exclusion in the vasculature to protect leaf blades and reproductive tissues from salt toxicity in rice. Plant J. 2017, 91, 657-670. [CrossRef]

39. Ishitsuka, S.; Yamamoto, M.; Miyamoto, M.; Kuwashiro, Y.; Imai, A.; Motose, H.; Takahashi, T. Complexity and conservation of thermospermine-responsive uORFs of SAC51 family genes in angiosperms. Front Plant Sci. 2019, 10, 564. [CrossRef]

40. Ndayiragije, A.; Lutts, S. Do exogenous polyamines have an impact on the response of a salt-sensitive rice cultivar to $\mathrm{NaCl}$ ? J. Plant Physiol. 2006, 163, 506-516. [CrossRef]

41. Cona, A.; Rea, G.; Angelini, R.; Federico, R.; Tavladoraki, P. Functions of amine oxidases in plant development and defence. Trends Plant Sci. 2006, 11, 80-88. [CrossRef] [PubMed]

42. Wimalasekera, R.; Tebartz, F.; Scherer, G.F. Polyamines, polyamine oxidases and nitric oxide in development, abiotic and biotic stresses. Plant Sci. 2011, 181, 593-603. [CrossRef] [PubMed]

43. Moschou, P.N.; Wu, J.; Cona, A.; Tavladoraki, P.; Angelini, R.; Roubelakis-Angelakis, K.A. The polyamines and their catabolic products are significant players in the turnover of nitrogenous molecules in plants. J. Exp. Bot. 2012, 63, 5003-5015. [CrossRef] [PubMed]

44. Quinet, M.; Ndayiragije, A.; Lefevre, I.; Lambillotte, B.; Dupont, G.C.C.; Lutts, S. Putrescine differently influences the effect of salt stress on polyamine metabolism and ethylene synthesis in rice cultivars differing in salt resistance. J. Exp. Bot. 2010, 61, 2719-2733. [CrossRef] [PubMed]

45. Zarza, X.; Atanasov, K.E.; Marco, F.; Arbona, V.; Carrasco, P.; Kopka, J.; Fotopoulos, V.; Munnik, T.; Gómez-Cadenas, A.; Tiburcio, A.F.; et al. Polyamine Oxidase 5 loss-of-function mutations in Arabidopsis thaliana trigger metabolic and transcriptional reprogramming and promote salt stress tolerance. Plant Cell Environ. 2017, 40, 527-542. [CrossRef] [PubMed]

46. Li, Q.F.; Sun, S.S.M.; Yuan, D.Y.; Yu, H.X.; Gu, M.H.; Liu, Q.Q. Validation of candidate reference genes for the accurate normalization of real-time quantitative RT-PCR data in rice during seed development. Plant Mol. Biol. Rep. 2010, 28, 49-57. [CrossRef]

(C) 2019 by the authors. Licensee MDPI, Basel, Switzerland. This article is an open access article distributed under the terms and conditions of the Creative Commons Attribution (CC BY) license (http://creativecommons.org/licenses/by/4.0/). 